\title{
Novo gênero neotropical de Spintharinae (Araneae, Theridiidae)
}

\author{
Maria Aparecida L. Marques ${ }^{1}$, Erica Helena Buckup ${ }^{1} \&$ Everton Nei Lopes Rodrigues ${ }^{2}$
}

1. Museu de Ciências Naturais, Fundação Zoobotânica do Rio Grande do Sul, Caixa Postal 1118, 90001-970, Porto Alegre, RS, Brasil. (maria-marques@fzb.rs.gov.br; erica-buckup@fżb.rs.gov.br)
2. Laboratório de Artrópodes, Instituto Butantan, Av. Vital Brazil, 1500, 05503-900, São Paulo, SP, Brasil. (enlrodrigues@yahoo.com.br)

ABSTRACT. New neotropical genus of Spintharinae (Araneae, Theridiidae). Neopisinus gen. nov. is proposed on the type species Neopisinus fiapo sp. nov., based on male and female specimens from Rio Grande do Sul, Brazil. Neopisinus differs from all Spintharinae by having the male palp with an enormous trifid conductor with two pointed structures and the third one apically bifurcated and by the characteristic shape of the theridioid tegular apophyses with a terminal and a dorsal lobes. The female genitalia has the inconspicuous opening anteriorly on a transversal sclerotized slit and internally a tubular longitudinal median thickening, where the copulatory ducts run in their initial trajectory. From northern Brazil, Neopisinus urucu sp. nov. is described based on both sexes. Seven species are transferred from Episinus to Neopisinus: N. bigibbosus (O. P.-Cambridge, 1896), N. bruneoviridis (Mello-Leitão, 1948), N. cognatus (O. P.-Cambridge, 1893), N. gratiosus (Bryant, 1940), N. longipes (Keyserling, 1884), N. putus (O. P.-Cambridge, 1894) and N. recifensis (Levi, 1964). The male of $N$. longipes and the female of $N$. recifensis are described for the first time. New records and illustrations of $N$. bruneoviridis are provided.

KEYWORDS. Brazil, spiders, new species, taxonomy.

RESUMO. Neopisinus gen. nov. é proposto com designação da espécie-tipo Neopisisnus fiapo sp. nov., com base em ambos os sexos, do Rio Grande do Sul, Brasil. Neopisinus distingue-se de todos os gêneros de Spintharinae pelo palpo do macho com enorme condutor trífido, com duas projeções afiladas e uma com ápice bifurcado; pela forma característica da apófise tegular de theridioideos com um lobo terminal e outro dorsal. Nas fêmeas, epígino com aberturas inconspícuas junto à fenda transversal no terço anterior e, internamente, por um espessamento mediano-longitudinal tubular, por onde correm os ductos de copulação em seu percurso inicial. Neopisinus urucu sp. nov. é descrita do norte do Brasil, com base em ambos os sexos. Sete espécies são transferidas de Episinus para Neopisinus: N. bigibbosus (O. P.-Cambridge, 1896), N. bruneoviridis (Mello-Leitão, 1948), N. cognatus (O. P.-Cambridge, 1893), N. gratiosus (Bryant, 1940), N. longipes (Keyserling, 1884), N. putus (O. P.-Cambridge, 1894) e N. recifensis (Levi, 1964). São descritos pela primeira vez o macho de $N$. longipes e a fêmea de $N$. recifensis. Novas ocorrências e ilustrações são apresentadas para $N$. bruneoviridis.

PALAVRAS-CHAVE. Brasil, aranhas, espécies novas, taxonomia.

Simon (1894) separou os 72 gêneros de Theridiidae por ele conhecidos em 18 tribos. A subfamília Spintharinae tem origem no grupo Spinthareae que incluía originalmente apenas Spintharus Hentz, 1850. O grupo Episineae incluía nove gêneros: Tomoxena Simon, 1895, Thwaitesia O. P.-Cambridge, 1881, Meotipa Simon 1894, Episinus Walckenaer in Latreille,1809, Penictis Simon, 1894, Plocamis Simon, 1894, Chrosiothes Simon, 1894, Janulus Thorell, 1881 e Episinopsis Simon, 1894.

Ao longo dos anos, a composição da subfamília Spintharinae foi sendo modificada constantemente com base em caracteres superficiais e inconsistentes. Um histórico taxonômico minucioso foi apresentado por Agnarsson (2004).

ARNedo et al. (2004), com base em análise filogenética utilizanddo caracteres moleculares, sugerem que Stemmops O. P.-Cambridge, 1894 pode pertencer à Spintharinae. Agnarsson (2004) formalmente inclui três gêneros em Spintharinae: Episinus, Spintharus e Thwaitesia, referindo que, provavelmente, Chrosiothes e Moneta O. P.-Cambridge, 1870 pertençam a este grupo. Sinapomorfias propostas para Spintharinae por Agnarsson (2004) e Agnarsson et al. (2007) incluem condutor desenvolvido, formado de várias partes, base da quelícera fina, abdômen com tubérculos laterais, colulo pequeno e pente do tarso IV com cerdas entalhadas na margem dorsal.

O gênero Episinus foi proposto para incluir a espécie-tipo européia E. truncatus Walckenaer, 1809 e contém atualmente cerca de 80 espécies mundiais (Platnick, 2011). Espécies centro e sul-americanas de Episinus foram revisadas por Levi (1955, 1964, 1967a, 1967b), que efetuou transferências, sinonímias e descrições, registrando 37 espécies. Nas Américas, o gênero apresenta maior diversidade em áreas tropicais, onde são frequentes espécies de pequeno porte, aproximadamente de $1 \mathrm{a} 4 \mathrm{~mm}$ de comprimento, com abdômen subtriangular e as de médio porte $(4 \mathrm{a} 7 \mathrm{~mm})$ com abdômen alongado que estavam representadas apenas por escassos espécimes ou conhecidas apenas por um dos sexos (Levi, 1955, 1964).

Levi (1964) comentou que, pela aparência, a alocação genérica de algumas espécies é incerta. Entre essas, encontra-se um grupo de sete espécies, diferenciado da espécie-tipo do gênero: Episinus cognatus O. P.Cambridge, 1893 do México, E. gratiosus Bryant, 1940 de Cuba, E. bruneoviridis Mello-Leitão, 1948 da Guiana e E. recifensis Levi, 1964 de Pernambuco, Brasil; duas espécies, uma do México e uma do Panamá, descritas por O. P.-CAmbridge $(1894,1896)$ respectivamente E. putus e E. bigibbosus e uma do Peru, E. longipes, proposta por KeYSERLING (1884), foram sinonimizadas com E. cognatus por LeVI $(1955,1964)$. WUNDERLICH (1986), ao examinar espécimes recentes e fósseis deste grupo de Episinus, caracterizado pelo condutor com três apófises, restabeleceu E. putus e E. bigibbosus e formalizou o grupo E. cognatus. Platnick (2011) citou E. longipes em nomen dubium.

KNoflach (1993) e Knoflach \& Thaler (2000) 
analisaram a estrutura dos órgãos sexuais de várias espécies de Episinus da Europa central (inclusive da espécie-tipo), do Mediterrâneo e das Ilhas Canárias e propuseram mais dois grupos: o grupo truncatus sensu stricto e o grupo theridioides.

Até o momento, para a América do Sul, são registradas 21 espécies de Episinus (Levi, 1955, 1964, 1967a, 1967b; Buckup \& Marques, 1992; Platnick, 2011), das quais 12 ocorrentes no Brasil. Atualmente, este gênero na Região Neotropical se apresenta heteromorfo e necessita ser delimitado.

O objetivo é propor um gênero novo para abrigar as espécies do grupo cognatus, que, até o momento, está mal-inserido em Episinus, descrever duas espécies novas e o sexo oposto de outras duas espécies.

\section{MATERIAL E MÉTODOS}

A nomenclatura dos escleritos do palpo do macho segue, em parte, Wunderlich (1986) e AgNARsSon et al. (2007). Para expansão e observação dos escleritos do palpo do macho, o mesmo foi imerso em KOH $10 \%$ por 20 minutos e transferido para água destilada. Para exame e ilustração da estrutura interna do epígino, o mesmo foi examinado imerso em ácido láctico $85 \%$. Medidas estão expressas em milímetros.

Abreviaturas utilizadas no texto: OMA, olhos médios anteriores; OMP, olhos médios posteriores; OLA, olhos laterais anteriores; OLP, olhos laterais posteriores.

Espécimes examinados pertencem às seguintes instituições, com suas respectivas siglas e curadores: IBSP, Instituto Butantan, São Paulo, Irene Knyzak, A. D. Brescovit; INPA, Instituto Nacional de Pesquisas da Amazônia, Manaus, A. L. Henriques; MCN, Museu de Ciências Naturais, Fundação Zoobotânica do Rio Grande do Sul, Porto Alegre, E. H. Buckup; MCTP, Museu de Ciências e Tecnologia, Pontifícia Universidade Católica do Rio Grande do Sul, Porto Alegre, A. A. Lise; MNRJ, Museu Nacional, Universidade Federal do Rio de Janeiro, Rio de Janeiro, A. B. Kury; MPEG, Museu Paraense Emílio Goeldi, Belém, A. B. Bonaldo.

\section{Neopisinus gen. nov.}

Espécie-tipo. Neopisinus fiapo sp. nov.

Etimologia. O nome genérico é uma combinação da palavra latina neo com sílabas de Episinus. Gênero gramatical masculino.

Diagnose. Neopisinus gen. nov. distingue-se de todos os gêneros de Spintharinae pelo palpo do macho com condutor enorme trífido, com duas projeções afiladas e uma com ápice bifurcado; pela forma característica da apófise tegular de theridioideos, semitubular, com um lobo terminal e outro dorsal (Figs 1-3, 9, 12, 15, 18); nas fêmeas pelo epígino com fenda transversal no terço anterior (Figs 4, 10, 13, 16, 19) e, internamente, por um espessamento mediano-longitudinal tubular, por onde correm os ductos de copulação em seu percurso inicial (Figs 5, 11, 14, 17, 20).

Descrição. Aranhas de tamanho médio a grande, comprimento total dos machos de 2,00 a 6,50 e das fêmeas 2,40 a 7,50. Carapaça subcircular, região cefálica estreita cerca da metade da largura da carapaça; região torácica elevada, a partir da fóvea com sulco longitudinal deprimido, geralmente atingindo a margem posterior; com estrias cefálicas e torácicas e cerdas fusiformes. Oito olhos em duas filas recurvadas, em vista dorsal; OMA maiores, circulares, diurnos e projetados anteriormente; demais olhos noturnos; OMA em cômoros mais ou menos desenvolvidos; OMP circulares; olhos laterais quase circulares, em pequenos cômoros. Clípeo projetado, altura cerca de um a dois diâmetros dos OMA, com uma reentrância abaixo dos olhos anteriores. Esterno mais longo do que largo, com ápice entre as coxas IV. Quelíceras cilíndricas, estreitadas para o ápice, promargem com um ou sem dentículo nas fêmeas e retromargem sem dentes. Lábio retangular, mais largo do que longo, fusionado e demarcado por uma linha ao esterno. Enditos levemente convergentes, cerca de duas a três vezes mais longos do que largos, margem anterior com serrula, cerdas apicais e escópula rala no terço apical da margem interna. Abdômen com dois tubérculos dorsais, geralmente alongado, subtriangular (N. graciosus) ou oval e sem tubérculos (N. recifensis e $N$. bruneoviridis); truncado anteriormente e com região posterior geralmente projetada em cone; algumas cerdas naviculares e fusiformes podem ser encontradas no dorso do abdômen de algumas espécies. Colulo pequeno com duas cerdas. Fiandeiras terminais. Pernas muito longas, com abundantes cerdas, geralmente fórmula $1423 \mathrm{em}$ ambos os sexos; tarsos com unha mediana longa e unhas laterais com dentes e falsas unhas apicais; pente do tarso IV com cerdas entalhadas na margem dorsal. Palpo da fêmea com uma unha longa com cinco dentes.

Palpo do macho (Figs 1-3, 9, 12, 15, 18). Fêmur longo, cerca de duas a três vezes mais longo que a tíbia; patela, tíbia e címbio aproximadamente do mesmo comprimento; címbio recortado apicalmente, com ápice retrolateral, portando três a quatro cerdas, base dorsal do címbio com uma pequena proeminência circular que se aloca numa concavidade distal da tíbia; gancho mediano-retrolateral no lado interno do címbio; alvéolo basal; pecíolo na hematodoca basal; subtégulo anelar, gradativamente se alargando ventralmente; tégulo com ducto curto, perfazendo apenas uma volta; êmbolo com origem ventro-retrolateral, muito longo e afilado, relativamente largo na base, parcialmente oculto atrás da porção flexível, translúcida e prolateral do condutor, ápice do êmbolo não visível, percurso em sentido horário (palpo esquerdo); apófise extrategular, acima da base embólica; condutor prolateralmente translúcido e ramificado na retrolateral com três projeções esclerotinizadas: a prolateral com ápice 
bifurcado e base membranosa, projeção mediana com ápice pontiagudo e base parcialmente membranácea e a retrolateral geralmente reta com ápice agudo ou rombo; apófise tegular de theridioideos prolátero-apical, semitubular com um lobulo dorsal e outro terminal com ápice articulado e agudo; apófise média dorsal, alongada, transversal, com uma depressão no ápice, onde se encaixa o gancho mediano do címbio.

Genitália das fêmeas. Epígino bem desenvolvido, geralmente delimitado anteriormente, semelhante a um cogumelo ou retangular, mais longo do que largo ou mais largo do que longo; com uma fenda transversal demarcada, no terço anterior (Figs 4, 10 13, 16, 19). Internamente, o epígino apresenta um espessamento mediano-longitudinal, visível por transparência em vista ventral; aberturas dos ductos de copulação anteriores, inconspícuas; dorsalmente, ductos estreitos perfazem uma a sete voltas ao redor das espermatecas alongadas, a seguir formam uma alça lateral até a base das mesmas, onde se curvam e ascendem em direção à fenda, sendo envolvidos medianamente pelo espessamento; ductos de fertilização na base lateral interna das espermatecas (Figs 5, 11, 14, 17, 20). Excepcionalmente, em $N$. bruneoviridis os ductos são largos e divergentes, não contornando as espermatecas (Fig. 17). O epígino frequentemente está coberto por uma substância, fortemente aderida à superfície, diferente dos tampões usuais, os quais são facilmente retirados junto com os prolongamentos que fecham as aberturas de copulação.

Inter-relação. Neopisinus gen. nov. apresenta as sinapomorfias da subfamília Spintharinae, registradas por AgNARsSon (2004) e AgNarsSOn et al. (2007).

Em todas as espécies européias de Episinus, KNOFLACH \& THALER (2000) notaram ausência de tubérculos atrás dos olhos médios anteriores e a presença de um dentículo em cada margem das quelíceras das fêmeas. Mecanismo de retenção do bulbo no palpo dos machos é formado por um gancho na margem distal do címbio. O palpo dos machos de Episinus sensu stricto tem êmbolo longo com base muito desenvolvida e a porção inicial encoberta pelo ápice do címbio. Base do êmbolo, internamente, com ducto longo e convoluto; condutor amplo e flexível. Mencionaram três apófises tegulares, as quais foram interpretadas por AgNARSSON (2007) como apófise média, apófise tegular de theridioideos, longa e não-ramificada, e apófise extrategular.

Diferenças no palpo dos machos das espécies sulamericanas de Neopisinus gen. nov. encontram-se na estrutura peculiar do condutor, prolateralmente, translúcido ou opaco e retrolateralmente trífido, na forma complexa da apófise tegular de theridioideos, semitubular, com dois lobos, base do êmbolo pouco desenvolvida e, internamente, ducto curto não-convoluto. $\mathrm{O}$ mecanismo de retenção do bulbo no palpo é constituído por um gancho medianoretrolateral, situado na face interna do címbio.

KNOFLACH \& THALER (2000) citaram que o epígino da fêmea de E. truncatus tem depressão mais larga do que longa, internamente, com ductos amplos, membranosos, divergentes para as laterais, espermatecas ovais com ápice alongado e saliente; espermatecas ou ductos de fertilização podem ou não estar conectados por uma ponte esclerotinizada e aberturas de copulação posteriores. Nas espécies sul-americanas de Neopisinus gen. nov., as fêmeas apresentam internamente um característico espessamento tubular, que envolve os ductos em sua porção inicial e as aberturas são anteriores, junto à fenda do epígino. No entanto, Levi (1955, fig. 22) citou e ilustrou aberturas de copulação posteriores em $N$. cognatus. Estruturalmente o epígino por ele ilustrado é muito semelhante ao das espécies sul-americanas.

Distribuição. Sul do México ao sul do Brasil.

Elenco das espécies de Neopisinus gen. nov.

Neopisinus bigibbosus (O. P.-Cambridge, 1896) comb. nov.

Episinus bigibbosus O. P.-CAmbridge, 1896:167, est. 20, fig. 8, síntipos + , Bugaba, Panamá; 1896:208, est. 26, fig. 6, ô. Examinados por WunderLICH, 1986:76, figs $110,116-125$.

Neopisinus bruneoviridis (Mello-Leitão, 1948) comb. nov.

Faiditus bruneoviridis Mello-Leitão, 1948:156, figs 4, 5, holótipo $\odot$, Cane Grove, Guiana.

Episinus bruneoviridis; LevI, 1955:70, Ô, ,, , figs 13, 19, 20, 34 .

Neopisinus cognatus (O. P.-Cambridge, 1893) comb. nov.

Episinus cognatus O. P.-CAmbridge, 1893:109, est. 15, fig. 2, đ, de Teapa, Tabasco, México. F. O. P.-CAmbridge, 1902:398, est. 37, figs 26 ô, 27 †. WunderLICH, 1986:76, figs 111, 126-129, examinou $\widehat{\jmath}$ do México, depositado no Natural History Museum, Londres, tendo dúvidas se o espécime se tratava do holótipo.

Neopisinus gratiosus (Bryant, 1940) comb. nov.

Episinus gratiosus BRYANT, 1940:313, fig. 65, holótipo $q$ de Oriente, Pico Turquino, Cuba. Examinado por LeVI, 1955:71, fig. 23; 1964:13, figs 1-3, o+; fig. 4 ô.

Neopisinus longipes (Keyserling, 1884) comb. nov.

Episinus longipes KeyserLING, 1884:207, est. 10, fig. 125, síntipos + e macho imaturo de Monterico, Ayacucho, Huanta, Peru (não examinados).

Neopisinus putus (O. P.-Cambridge, 1894) comb. nov.

Episinus putus O. P.-CAMBridge, 1894:132, est. 18, fig. 7, holótipo đ̂ de Teapa, Tabasco, México. F. O. P.CAmbridge, 1902:397, est. 37, fig. 25, §̂. Examinado por WUNDERLICH, 1986:76, figs 112, 130-133, holótipo ${ }^{\top}$. 

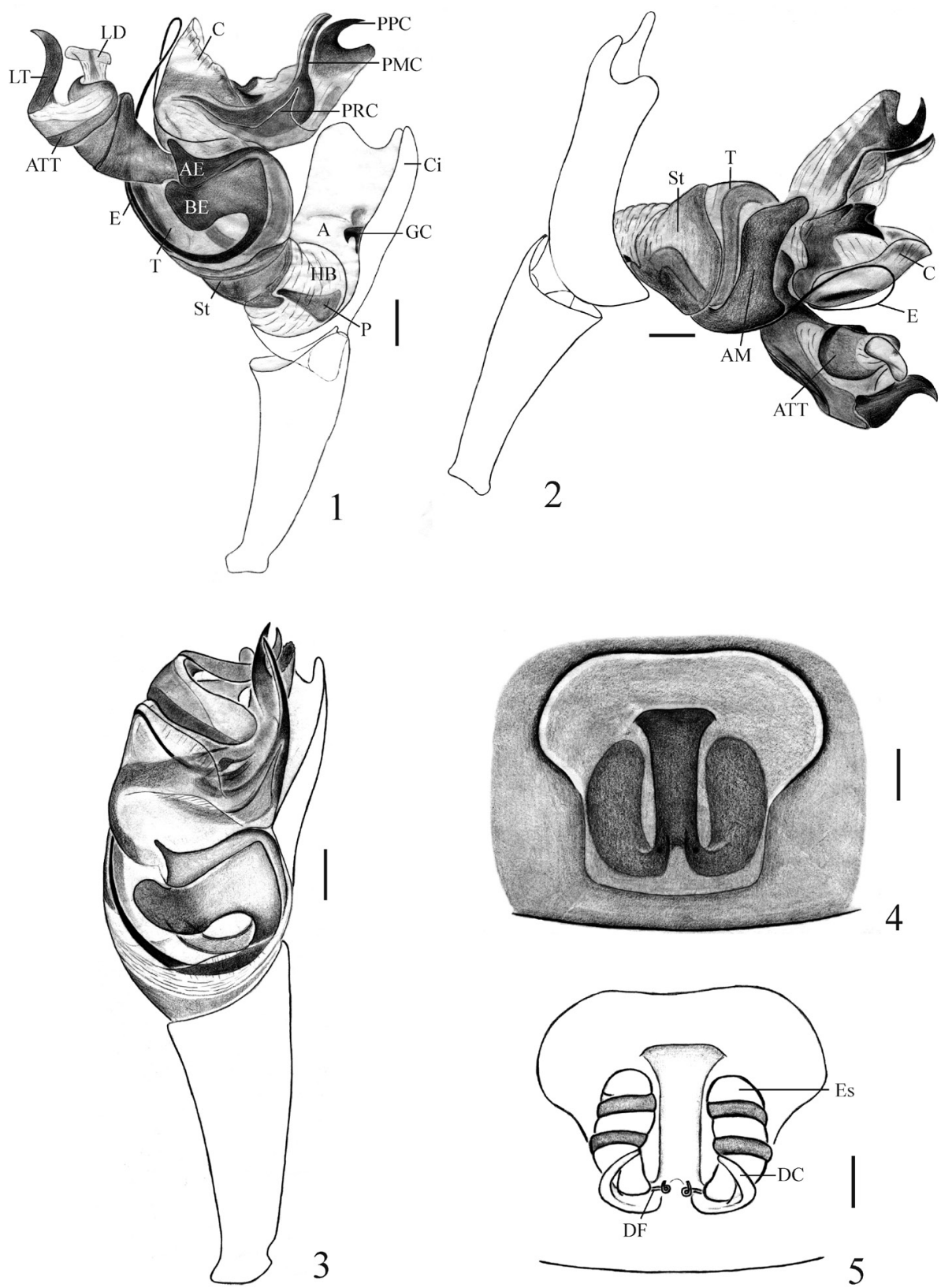

Figs. 1-5. Neopisinus fiapo sp. nov. Palpo esquerdo expandido: 1, ventral; 2, dorsal; 3, palpo, ventral; epígino: 4, ventral; 5, dorsal (A, alvéolo; $\mathrm{AE}$, apófise extrategular; AM, apófise média; ATT, apófise tegular de theridioideos ; BE, base do êmbolo; C, condutor; Ci, címbio; DC, ducto de copulação; DF, ducto de fertilização; E, êmbolo; ES, espermateca; GC, gancho do címbio; HB, hematodoca basal; LD, lobo dorsal da ATT; LT, lobo terminal da ATT; P, pecíolo; PMC, projeção mediana do condutor; PPC, projeção prolateral do condutor; PRC, projeção retrolateral do condutor; St, subtegulo; T, tégulo). Escalas $0,1 \mathrm{~mm}$.

Neopisinus recifensis (LevI, 1964) comb. nov. Episinus recifencis LeVI, 1964:12, holótipo ô, fig. 8, Recife, Pernambuco, Brasil (não examinado).

Mais duas novas espécies descritas a seguir.

\section{Neopisinus fiapo sp. nov.}

(Figs 1-8)

Episinus cognatus; Bonaldo et al., 2007:148, non E. cognatus O. P. Cambridge, 1893 (identificação errônea).

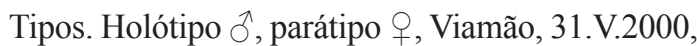
A. B. Bonaldo col. (MCN 32708). Parátipos:
Tigre, Gravataí, 15.VII.2000, A. B. Bonaldo col. (MCN 46803); Oै $^{2}$ Barra do Ribeiro, 16.XII.2003, Equipe Probio col. (MCN 36738); §̂, Guaíba, 28.IV.1995, A. A. Lise et al. col. (MCTP 6084); 9 , 02.VI.1995, A. A. Lise et al. col. (MCTP 6708); 9 , Parque Estadual do Turvo, Derrubadas, 19-22.X.2004, R. Ott et al. col. (MCN 38502), todos do Rio Grande do Sul, Brasil; 2 , , +, Estação Ecológica de Assis, Assis, 25-30.XI.2002, Equipe Biota col. (IBSP 85784); 今̃, ᄋ, Parque Natural Municipal da Serra de Itapety, Mogi das Cruzes, 13-19.X.2003, Equipe Biota col. (IBSP 85772), todos de São Paulo, Brasil.

Etimologia. O substantivo específico fiapo (= fiozinho) refere-se à delgada e reduzida projeção retrolateral do condutor, difícil de ser observada. 
Diagnose. Machos de Neopisinus fiapo sp. nov. são similares aos de $N$. cognatus e $N$. putus (vide WUNDERLICH, 1986, figs 111, 112) pelo címbio quase tão longo quanto à tíbia. Distinguem-se dessas espécies pelo condutor com projeção retrolateral muito curta com ápice afilado, sobreposta à projeção mediana, difícil de ser observada (Figs 1, 3). Fêmeas de $N$. fiapo assemelham-se às de $N$. cognatus (sensu LeVI, 1955, figs 21, 22, sob Episinus) pelo epígino em forma de cogumelo (Fig. 4); distinguem-se de $N$. cognatus pela fenda mediana larga e, internamente, pelos ductos afastados entre si (Fig. 5). Em N. cognatus, a largura da fenda é bem-estreita e, internamente, os ductos perfazem três voltas juntas ao redor das espermatecas.

Nota. Machos e fêmeas de N. fiapo sp. nov. foram coligidos juntos em várias localidades do sul e sudeste do Brasil.

Descrição. Macho (holótipo). Carapaça amareloclara, a partir dos olhos médios posteriores com uma faixa longitudinal marrom-escura que atinge o sulco; laterais com três manchas marrons de cada lado (Figs 6, 7). Quelíceras amarelo-claras. Esterno amarelo-claro com laterais pigmentadas de marrom. Pernas amareloclaras; fêmures anteriores com manchas ventrais e prolaterais pigmentados de marrom. Abdômen longo, margem anterior truncada, a partir dos tubérculos laterais em cone posterior, com fiandeiras terminais; dorso com abundantes retículos brancos, região mediana longitudinal despigmentada no centro; tubérculos laterais pigmentados de preto e região posterior estriada transversalmente, as estrias anteriores mais escuras do que as posteriores (Figs 6, 7). Ventre despigmentado, laterais pigmentadas de branco com alguns traços pretos.

Medidas. Comprimento total 4,50. Carapaça, comprimento 1,48, largura 1,22. Abdômen, comprimento 3,00 . Pernas 1423. Comprimento perna I: fêmur 3,25; patela+tíbia 3,70 ; metatarso 3,90 ; tarso 1,15 . II: 1,90 ; 2,10; 2,$05 ; 0,80$. III: 1,$50 ; 1,45 ; 1,50 ; 0,70$. IV: 3,$20 ; 3,00$; 3,$34 ; 1,05$. Comprimento total: 12,$00 ; 6,85 ; 5,15 ; 10,59$.

Olhos médios anteriores distantes um do outro por quase seu diâmetro e meio e dos OLA por cerca do raio dos OMA; OMP afastados entre si por aproximadamente seu diâmetro e dos OLP por pouco mais do diâmetro dos OMP. Altura do clípeo igual ao diâmetro dos OMA.

Fêmea (parátipo MCN 32708, Viamão). Abdômen com larga faixa transversal preta e declive posterior acentuado (Fig. 8). Demais aspectos e coloração como no macho.

Medidas. Comprimento total 5,90. Carapaça, comprimento 1,78, largura 1,48. Abdômen, comprimento 4,20 . Pernas 1423. Comprimento perna I: fêmur 3,55; patela+tíbia 3,70; metatarso 4,00; tarso 1,10 . II: 2,20 ; 2,$00 ; 2,05 ; 0,90$. III: 1,$75 ; 1,45 ; 1,50 ; 0,80$. IV: 3,45 ; 3,$05 ; 3,60 ; 1,20$. Comprimento total: 12,$35 ; 7,15 ; 5,50$; 11,30 .
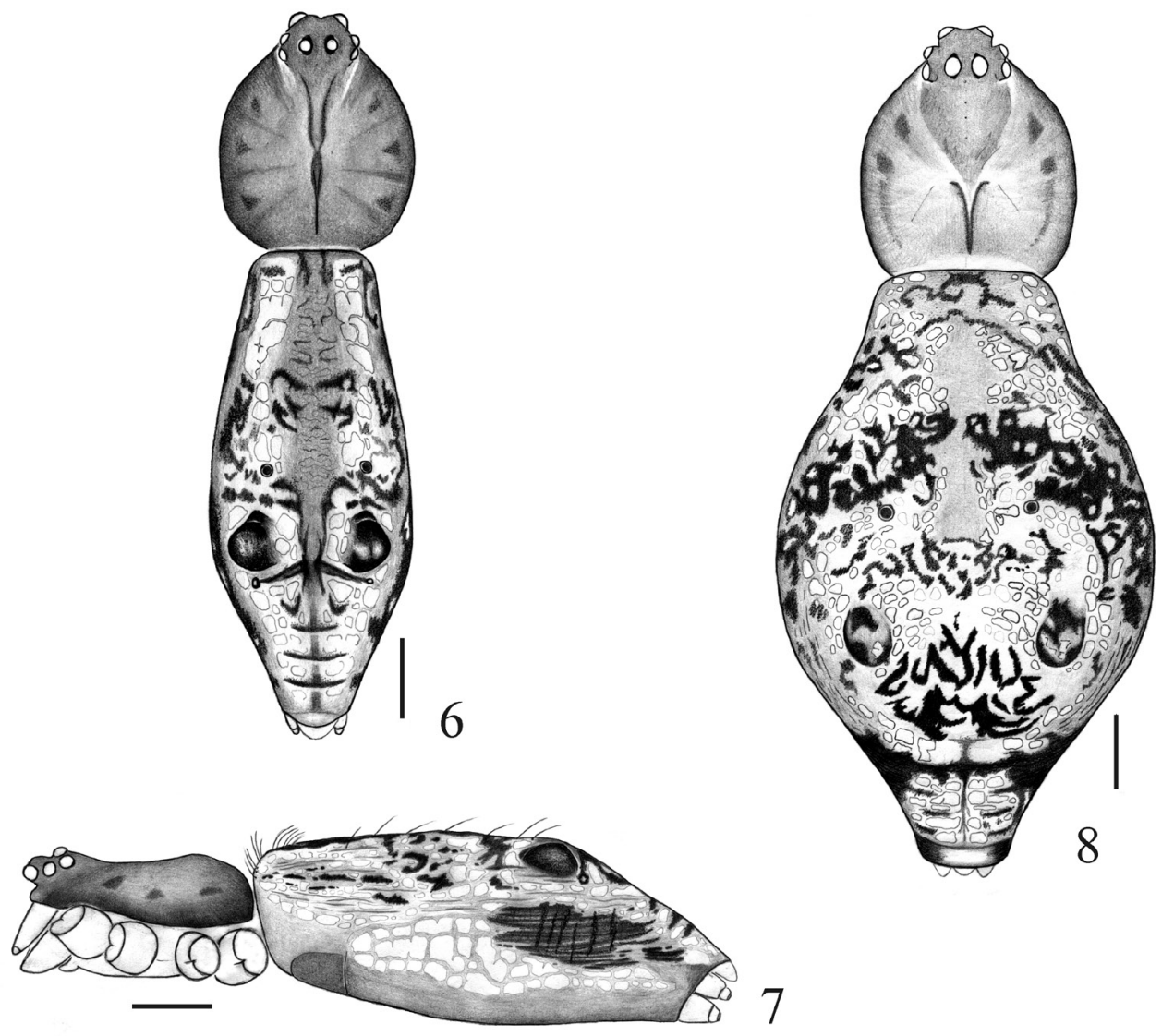

Figs. 6-8. Neopisinus fiapo sp. nov. Corpo do macho: 6, dorsal; 7, lateral; 8, corpo da fêmea, dorsal. Escalas 0,5 mm. 
Olhos médios anteriores separados um do outro por cerca de três quartos do seu diâmetro e dos OLA por menos que um quarto do diâmetro dos OMA; OMP distantes um do outro e dos OLP por cerca de três quartos do diâmetro dos OMP. Altura do clípeo igual ao diâmetro dos OMA.

Variação. Comprimento total dos machos $(\mathrm{n}=10)$ 3,90-4,80; carapaça 1,35-1,50; fêmur I 3,15-3,65. Fêmeas $(n=10)$ 5,05-6,00; carapaça 1,60-1,80; fêmur I 3,3-3,75. A fenda do epígino pode ser reta, em arco, um pouco angulosa, com um recorte mediano posterior ou até assimétrica. O número de voltas do ducto de copulação em cada espermateca, em vista dorsal, varia de uma a três voltas incompletas. Um espécime com espermatecas menores apresentou apenas uma volta dorsal e duas ventrais. No momento, como não foi encontrada variação no palpo dos machos, essas fêmeas foram consideradas coespecíficas. $\mathrm{O}$ grau de pigmentação preta no abdômen de machos e fêmeas é variável.

Distribuição. Brasil (Minas Gerais, Rio de Janeiro, São Paulo e Rio Grande do Sul).

Material adicional examinado. BRASIL, Minas Gerais: Juatuba (Serra Azul), ô, 2 ๆ, 18-24.IV.2002, Equipe Biota col. (IBSP $85777,85778)$ e 3 , o (MCN 43579, 43580); Catas Altas (Reserva Particular de Patrimônio Natural Serra do Caraça), +o, 24.IV01.V.2002, Equipe Biota col. (IBSP 85776); Belo Horizonte (Estação Ecológica da Universidade Federal de Minas Gerais), ô, 우, V.2001, E. O. Machado col. (MCN 34124); Rio de Janeiro: Bom Jardim, ô, 21-28.VI.2003, M. Hoffmann col. (MCN 39833); Pinheiral (Fazenda Santa Helena), ô, ㅇ, 05-11.XI.1999, A. D. Brescovit et al. col. (IBSP $85764,85765)$ e $\delta$, 오 (MCN 42071); Resende (Parque Nacional de Itatiaia), $\pi$, + , 08-15.VI.2001, Equipe Biota col. (IBSP 85769, 85770); Volta Redonda (Floresta da Cicuta), ô, ㅇ, 11-18.VI.2001, Equipe Biota col. (IBSP 85762, 85763) e $\hat{\sigma}$, \& (MCN 43577); São Paulo: Miracatu (Fazenda Itereí),, , 20-26.IX.2001, Equipe Biota col. (IBSP 85761); Assis (Estação Ecológica de Assis), 3 ô, ㅇ, 25-30. XI.2002, Equipe Biota col. (MCN 43590); Botucatu, Oे, o, 02.X.1986 e 07.VII.1988, I. Rinaldi \& L. Forti col. (MCN 34342, 34343); Itapetininga (Estação Ecológica de Angatuba), đo, ๆ, 11-16.XI.2002, Equipe Biota col. (IBSP 85774, 85775) e ô (MCN 43578); São Paulo (Parque Estadual da Cantareira), ô, q, 20.VIII.2000 e 20.XII.2000, R. Pinto da Rocha et al. col. (MCN 41823, 41824), 2 9, 01.V.2001 e 24. VI. 2001, R. Pinto da Rocha et al. col. (MCN 41821, 41822); Guarulhos (Parque Estadual da Cantareira), ㅇ, 16-22.VII.2001, Equipe Biota col. (IBSP 85767); São Paulo (Parque Estadual do Jaraguá), đ̂, + , 14-19.X.2002, Equipe Biota col. (IBSP 51096, 85766) e o , 4 O (MCN 42008, 42009); Ubatuba (Parque Estadual da Ilha Anchieta), ㅇ, 23-30.VII.2001, Equipe Biota col. (IBSP 85768); Mogi das Cruzes (Parque Natural Municipal da Serra do Itapety), ô, 13-19.X.2003, Equipe Biota col. (IBSP 85773); Ilhabela (Parque Estadual de Ilhabela), o, 09-15.X.2001, Equipe Biota col. (IBSP 85771); Paraná: Foz do Iguaçu (Parque Estadual da Foz do Iguaçu), q, 03-12.II.2002, Equipe Biota col. (IBSP 85779) e + (MCN 43588); Rio Grande do Sul: ${ }^{\lambda}$, ㅇ (sem especificação de localidade e data), Pe. Rambo col. (MNRJ 41761, 42070); Derrubadas (Parque Estadual do Turvo), ô, 3 क, 11-18.I.2002, Equipe Biota col. (MCN 43589) e 2 ภ, 4 +, 11-18.I.2002, Equipe Biota col. (IBSP 85780-85783); Carazinho, ㅇ, 10.XI.1979, A. A. Lise col. (MCN 8688); Estrela Velha (Barragem Itaúba), ㅇ, 28.X.1999, A. B. Bonaldo col. (MCN 31674); Salto do Jacuí, 2 + , 19.X.1998, A. B. Bonaldo col. (MCN 30904); Santa Maria,, , 28.VII.1998, L. Indrusiak \& C. Kotzian col. (MCN 32445); +, 27.V.2000, L. Indrusiak col. (MCN 34476); Maquiné, ㅇ, 09.V.2008, E. N. L. Rodrigues col. (MCN 46780); Triunfo, +, 28.XI.1977, A. A. Lise col. (MCN 7353); (Estação Ambiental Braskem), o, 26.II.2010, M. A. L. Marques col. (MCN 47058); 우, 11.VI.2010, M. R. M. Poeta col. (MCN 47206); 今, 04.XII.2009, E. N. L. Rodrigues col. (46828); Gravataí (Morro do Tigre), 2
3ૈ, 15.VII.2000, A. B. Bonaldo col. (MCN 32755); 은 Glorinha, 16.VII.2000, A. B. Bonaldo col. (MCN 32796); Santo Antonio da Patrulha, ô, 18.VII.2000, A. B. Bonaldo col. (MCN 32745); Guaíba, 2 o, 17.III.1995, 14.VII.1995, A. A. Lise et al. col. (MCTP 5909, 6691); Porto Alegre, ô, 03.IX.1989, R. Arruda col. (MCN 18626); †, 28.IV.1991, D. Picada col. (MCTP 3088); (Jardim Botânico), ở, 11.XI.1994, A. B. Bonaldo col. (MCN 26132); (Morro Santana), ,, 16.V.1981, A. A. Lise col. (MCN 4131); (Morro São Pedro), ô, o, 18.IX.2003, R. Ott \& A. Barcelos col. (MCN 36218); Viamão, 7 đ̊, 3 +, 06.V.1994, 23.IX.1994, 07.X.1994, 12.VIII.1994, A. A. Lise et al. col. (MCTP 4712, 5203, 5520, 5552); 2 ㅇ, 24.III.1995, 27.VII.1995, A. A. Lise et al. col. (MCTP 5921, 6519); (Itapuã), ㅇ, 05.II.1975, A. A. Lise col. (MCN 2486); (Parque Saint Hilaire), Ô, 07.V.1976, H. Bischoff col. (MCN 4254); Barra do Ribeiro, ㅇ, 13.V.2003, R. S. de Araujo col. (MCN 35894); Dom Feliciano, , 18,19.III.2000, A. B Bonaldo col. (MCN 32242); Tapes, ô, 14.V.2003, Equipe Probio col. (MCN 35842).

\section{Neopisinus longipes (Keyserling, 1884) comb. nov.} (Figs 9-11)

Episinus longipes Keyserling, 1884: 207, est.10, fig. 125, fêmea e macho imaturo, Monterico, altitude 900 m, Ayacucho, Huanta, Peru, depositados na Sammlung der Universität, Varsóvia, tipo perdido; Roewer, 1942: 450; Platnick, 2011, nomen dubium.

Nota. Keyserling (1884) descreveu Episinus longipes sobre uma fêmea procedente do Peru, com epígino retangular, mais longo do que largo. Levl (1964) comentou que o tipo de E. longipes está perdido. Assumimos que as fêmeas ora examinadas pertencem a Neopisinus longipes pela forma retangular do epígino da fêmea (vide Keyserling, 1884, fig. 125). Machos e fêmeas foram colecionados juntos em várias localidades do norte, centro-oeste e sudeste do Brasil.

Diagnose. Machos de Neopisinus longipes separam-se daqueles de $N$. cognatus e $N$. putus (WuNDERLICH, 1986, figs 111, 112, respectivamente) pela base oblíqua do êmbolo e pelo início da porção afilada do êmbolo junto ao ângulo da margem retrolateral do címbio e pela projeção retrolateral do condutor de comprimento médio (Fig. 9). Fêmeas distinguem-se das demais espécies do gênero pelo epígino retangular, mais longo do que largo (Figs 10, 11).

Descrição. Macho (MCN 46078, São Gabriel da Cachoeira). Coloração igual à de Neopisinus fiapo sp. nov.

Medidas. Comprimento total 5,60. Carapaça, comprimento 1,65, largura 1,35. Abdômen, comprimento 3,40. Pernas 1423. Comprimento perna I: fêmur 3,95; patela+tíbia 4,40; metatarso 4,65; tarso 1,25 . II: 2,30; 2,$40 ; 2,30 ; 0,90$. III: 1,$75 ; 1,60 ; 1,50 ; 0,75$. IV: 3,55 ; 3,$50 ; 4,05 ; 1,35$. Comprimento total: 14,$25 ; 7,90 ; 5,60$; 12,45 .

Olhos médios anteriores separados um do outro por quase um diâmetro dos OMA e muito próximos dos OLA; OMP distantes um do outro por cerca de três quartos do seu diâmetro e afastados por um terço do seu diâmetro dos OLP. Altura do clípeo pouco mais do que um diâmetro dos OMA.

Fêmea (MCN 46079, São Gabriel da Cachoeira). Coloração igual a do macho. 


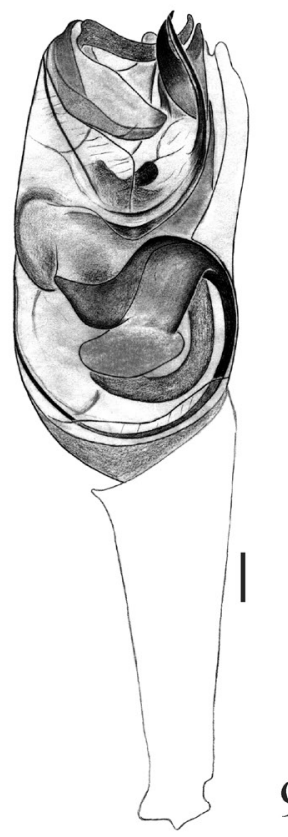

9

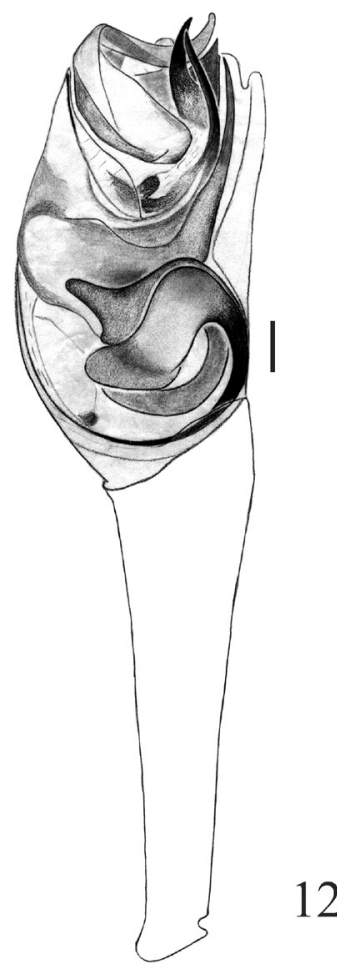

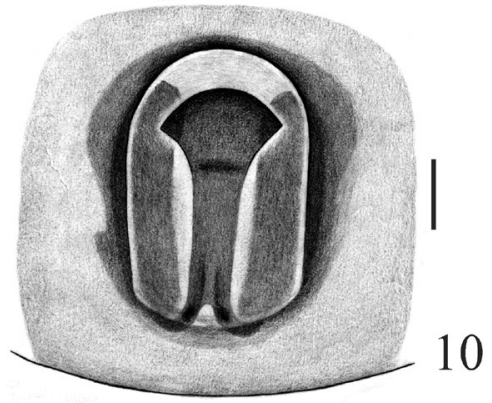
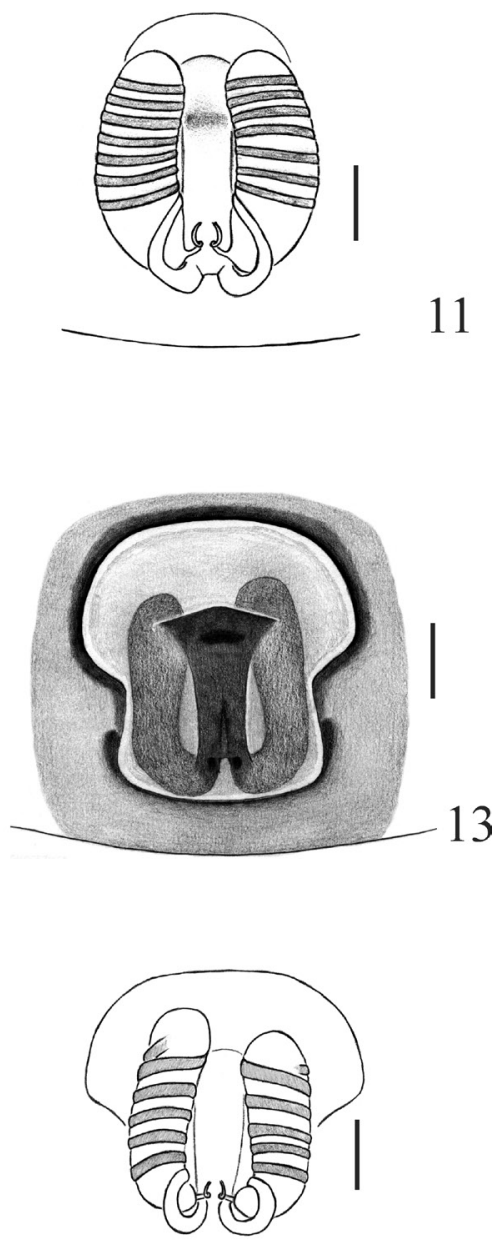

14

Figs. 9-14. Neopisinus longipes (Keyserling, 1884). 9, palpo, ventral; epígino: 10, ventral; 11, dorsal. Neopisinus urucu sp. nov. 12, palpo, ventral; epígino: 13, ventral; 14 dorsal. Escalas $0,1 \mathrm{~mm}$.

Medidas. Comprimento total 6,60. Carapaça, comprimento 1,95, largura 1,75. Abdômen, comprimento 4,90. Pernas 1423. Comprimento perna I: fêmur 4,00; tíbia+patela 4,40; metatarso 4,45; tarso 1,10 . II: 2,50 ; 2,$40 ; 2,25 ; 0,90$. III: 1,$95 ; 1,70 ; 1,75 ; 0,85$. IV: 4,15; 3,75; 4,$20 ; 1,35$. Comprimento total: 13,$95 ; 8,05 ; 6,25 ; 13,45$.

Olhos médios anteriores afastados um do outro por dois terços do seu diâmetro e por um quinto do seu diâmetro dos OLA. Olhos médios posteriores separados um do outro por três quartos do seu diâmetro e pelo seu raio dos OLP. Altura do clípeo cerca de um diâmetro e um terço dos OMA.

Variação. Comprimento total dos machos $(\mathrm{n}=7)$ 4,10-5,60; carapaça 1,50-1,70; fêmur I 3,75-4,05. Fêmeas $(\mathrm{n}=6)$ 5,25-6,60; carapaça 1,70-2,00; fêmur I 3,60-4,20. Algumas fêmeas apresentam a curvatura da fenda do epígino um pouco angulosa; em um exemplar a fenda é triangular. O número de voltas do ducto em cada espermateca varia de cinco a sete. $\mathrm{O}$ grau de pigmentação preta no abdômen de machos e fêmeas é variável. 
Distribuição. Peru (Monterico) e Brasil (Roraima, Amazonas, Rondônia, Paraíba, Mato Grosso, Mato Grosso do Sul, Minas Gerais e Espírito Santo).

Material adicional examinado. BRASIL, Roraima: Alto Alegre (Ilha de Maracá), 2 +, 31.I.-14.II.1992, A. A. Lise \& A. B. Bonaldo col. (MCTP 2081); Amazonas: São Gabriel da Cachoeira

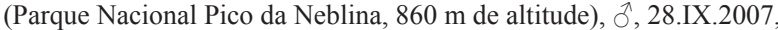
A. A. Nogueira col. (INPA); 2 9, 28-29.IX.2007, D. F. Candiani col., $860 \mathrm{~m}$ (INPA); 2 , 25.IX.2007, N. F. Lo-Man-Hung col., $400 \mathrm{~m}$ altitude (MCN 46078); + , 29.IX.2007, A. A. Nogueira col., 860 m (MCN 46079); Paraíba: Areia (Reserva da Mata do Pau Ferro), ô, ㅇ, 23-29. IX.1999, A. D. Brescovit et al. col. (IBSP 50526); Rondônia: Ouro Preto do Oeste (Fazenda Nova Umas), đ̃, XII.1983, A. Cerrutti col. (MNRJ 2005); Mato Grosso: Poconé, ô, 04-10.VIII.1992, A. A. Lise col. (MCTP 2584); Mato Grosso do Sul: Dois Irmãos do Buriti, 2 \%, +, 31.IV-06.VII.1999, A. D. Brescovit et al. col. (IBSP 85785, 85786) e $\partial$, ,, (MCN 43599, 43600); Minas Gerais: Taiobeiras, $\partial \hat{2}, 0+, 08-17$. IV.2002, Equipe Biota col. (IBSP 85787, 85788); Espírito Santo: São Mateus (Reserva Florestal da Companhia Vale do Rio Doce), ô, o , 0610.I.1998, A. J. Santos et al. col. (MCN 32380); Conceição da Barra (Parque Estadual de Itaúnas), ô, ㅇ, 15.XII.2002-06.III.2003, Equipe Biota col. (IBSP 85789, 85790) e 9 (MCN 43601).

\section{Neopisinus urucu sp. nov.}

(Figs 12-14)

Episinus bigibbosus; RicetTI \& Bonaldo, 2008:96, non E. bigibbosus O. P.-Cambridge, 1896 (identificação errônea).

Tipos. Holótipo đ̊ , Porto Urucu, Coari, Amazonas, X.2006, S. C. Dias col. (MPEG 12967). Parátipos: ㅇ, da mesma localidade do holótipo, VII.2006, S. C. Dias col. (MPEG 12664); ㅇ, VII.2006, L. T. Miglio col. (MPEG 12596); 9 , Parque Nacional Pico da Neblina (altitude 100 m), São Gabriel da Cachoeira, Amazonas, 24.IX.2007, D. F. Candiani col. (MCN 46080); $\widehat{\jmath}$, Serra do Cachimbo, Novo Progresso, Pará, 03-06.IV.2004, J. Ricetti col. (MCN 38205); todos do Brasil.

Etimologia. O nome específico é um substantivo em aposição referente à localidade-tipo.

Diagnose. Machos de Neopisinus urucu sp. nov. assemelham-se aos de $N$. bigibbosus pela tíbia mais longa do que o címbio e pela projeção retrolateral do condutor longa em ambas as espécies, mas distinguem-se pela base oblíqua do êmbolo (Fig. 12); em $N$. bigibbosus (vide O. P.-CAmbridge, 1896, fig. 6; Wunderlich, 1986, fig. 110), a base do êmbolo é transversal. Fêmeas separam-se das espécies com epígino em forma de cogumelo pelo espessamento mediano deprimido transversalmente, próximo à fenda (Fig. 13); internamente, pelas espermatecas longas com ápice ultrapassando a fenda e ductos perfazendo cinco voltas ao redor das espermatecas (Fig. 14).

Descrição. Macho, holótipo. Carapaça, pernas e esterno amarelos. Abdômen, muito longo e estreito, amarelado, dorso todo salpicado de pequenas manchas marrons; tubérculos laterais reduzidos com pigmento marrom; recoberto por longas macrocerdas. Ventre amarelo.

Medidas. Comprimento total 5,20. Carapaça, comprimento 1,60, largura 1,35. Abdômen, comprimento 3,65. Pernas 1423. Comprimento perna I: fêmur 4,25; tíbia+patela 4,95; metatarso 5,30; tarso 1,20 . II: 2,50;
2,55; 2,$75 ; 0,85$. III: 1,$80 ; 1,60 ; 1,95 ; 0,75$. IV: 4,00; 3,85; $4,95,1,25$. Comprimento total: 15,$70 ; 8,65 ; 6,10 ; 14,05$.

Olhos médios anteriores separados entre si por aproximadamente três quartos do seu diâmetro e próximos dos laterais. Olhos médios posteriores afastados um do outro por seu diâmetro e pelo seu raio dos OLP. Altura do clípeo aproximadamente um diâmetro dos OMA.

Fêmea, parátipo (MPEG 12664, Coari). Coloração igual à do macho, exceto pelo dorso do abdômen com pigmento branco. Abdômen longo e estreito como no macho.

Medidas. Comprimento total 7,10. Carapaça, comprimento 1,90, largura 1,60. Abdômen, comprimento 5,10. Pernas 4123. Comprimento perna I: fêmur: 4,15; patela+tíbia 4,55; metatarso 4,80; tarso 1,10 . II: 2,70 ; 2,$50 ; 2,50 ; 0,85$. III: 2,$15 ; 1,75 ; 2,00 ; 0,90$. IV: 4,60; 3,95; 5,$05 ; 1,40$. Comprimento total: 14,$60 ; 8,55 ; 6,80 ; 15,00$.

Olhos médios anteriores afastados um do outro por mais de três quartos do seu diâmetro e por um quarto dos OLA. Olhos médios posteriores separados entre si por aproximadamente a metade do seu diâmetro e por menos do seu raio dos laterais. Altura do clípeo um diâmetro e meio dos OMA.

Variação. Comprimento total dos machos $(n=3)$ 4,55-5,20; carapaça 1,50-1,60; fêmur I 3,80-4,25. Fêmeas $(n=5)$ 7,10-7,50; carapaça 1,80-1,95; fêmur I $4,00-4,20$. A forma das espermatecas varia, às vezes é reniforme ou assimétrica.

Distribuição. Brasil (Amazonas e Pará).

Material adicional examinado. BRASIL, Amazonas: São Gabriel da Cachoeira (Parque Nacional Pico da Neblina, altitude 400 m), 2 , 25, 27.IX.2007, D. F. Candiani col., (INPA); Coari (Porto Urucu), ふึ, 14.VII.2003, A. B. Bonaldo col. (MPEG 1494); + 21.VII.2003, A. B. Bonaldo col. (MPEG 1483); ․, IX.2006, S. C. Dias col. (MPEG 12813); Pará: Novo Progresso (Serra do Cachimbo), đ̋, 03-06.IV.2004, J. Ricetti col. (MPEG 1260); †, 02.IV.2004, J. A. P. Barreiros col. (MPEG 1262) e $q$ (MCN 38210).

\section{Neopisinus bruneoviridis (Mello-Leitão, 1948) comb. nov.}

(Figs 15-17)

Faiditus bruneoviridis Mello-Leitão, 1948:156, figs 4, 5, holótipo + , Cane Grove, Guiana, no Natural History Museum, Londres (não examinado).

Episinus bruneoviridis; LeVI, 1955:70, figs 13, 19, 20, 34, ô, ๆ; 1964:11; Brignoli, 1983: 405; Platnick, 2011.

Diagnose. O palpo do macho de Neopisinus bruneoviridis, semelhante ao de $N$. recifensis pela apófise tegular de theridioideos compacta e opaca (vide LEVI, 1955, fig. 13), mas distingue-se desta espécie pela projeção retrolateral do condutor, estreita e afilada (Fig. 15) e pelo padrão de coloração do abdômen com fólio característico (LevI, 1955, fig. 34). Fêmeas distinguem-se de todas as demais espécies do gênero pela fenda do epígino larga, triangular e com ângulos laterais projetados (Fig. 16); internamente, pelos ductos excepcionalmente largos, 
situados junto às laterais das espermatecas (Fig. 17).

Descrição. LeVI, 1955:70, ô, ๆ, figs 13, 19, 20, 34.

Distribuição. Panamá (Barro Colorado Island), Trinidad, Guiana (Levi, 1955) e Brasil (Roraima e Rio de Janeiro).

Material adicional examinado. BRASIL, Roraima: Ilha de Maracá (rio Uraricoera, Estação Ecológica de Maracá), q, 31.I-14. II.1992, A. B. Bonaldo col. (MCN 22409); Rio de Janeiro: Teresópolis (Parque Nacional da Serra dos Órgãos), ô, 18-22.VIII.2001, Equipe Biota col. (IBSP 85760) e đ̊ (MCN 43576).
Neopisinus recifensis (Levi, 1964) comb. nov.

(Figs 18-20)

Episinus recifensis LevI, 1964:12, fig. 8, holótipo ô, Recife, Pernambuco, Brasil, depositado no Senckenberg Museum, Frankfurt, n.RII /6323/1; Brignoli, 1983:406; Platnick, 2011.

Diagnose. Machos de Neopisinus recifensis, similares aos de $N$. bruneoviridis pela apófise tegular de theridioideos opaca e compacta, distinguem-se pela projeção retrolateral do condutor, longa e larga (Fig. 18). Fêmeas podem ser
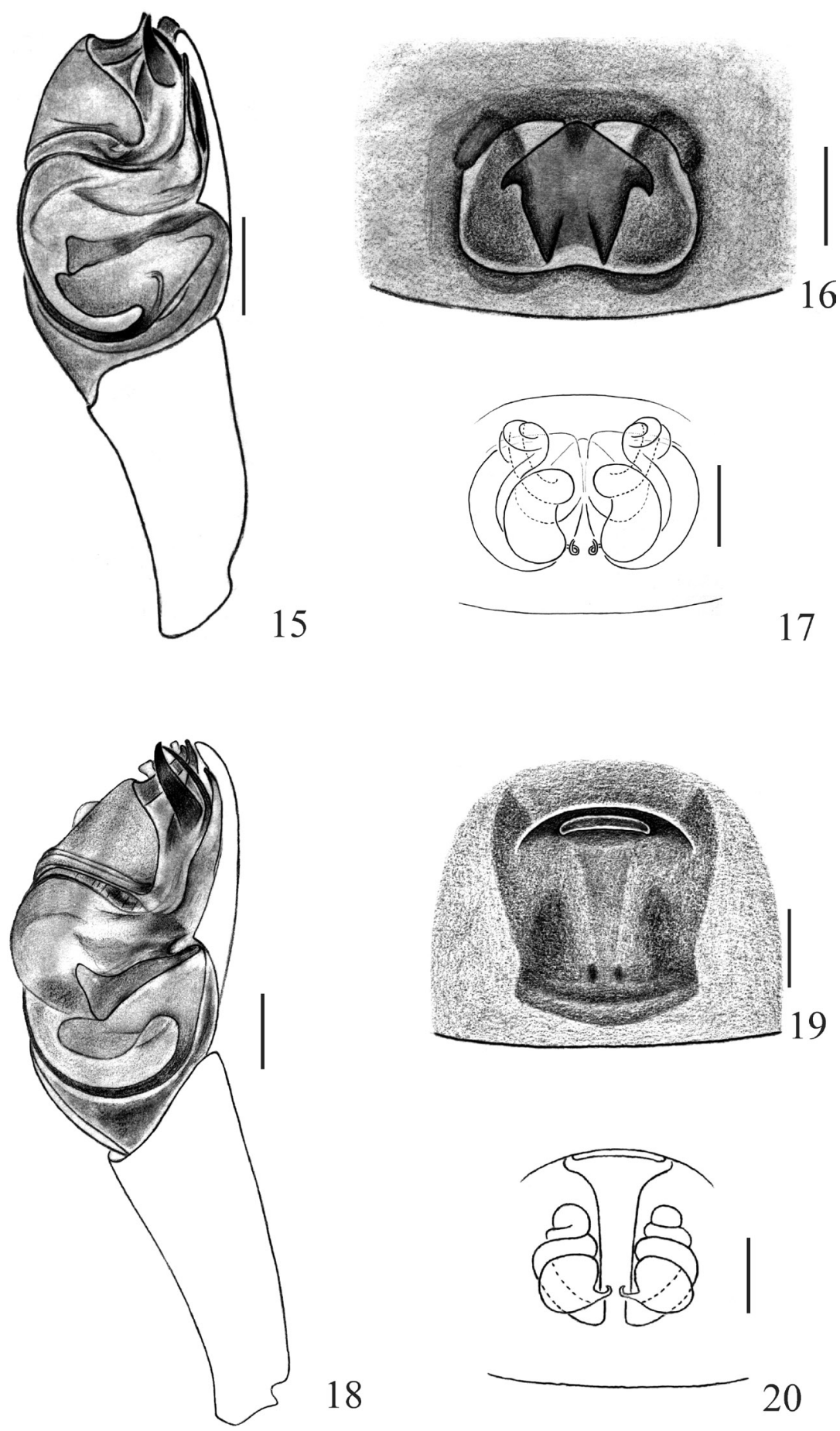

18

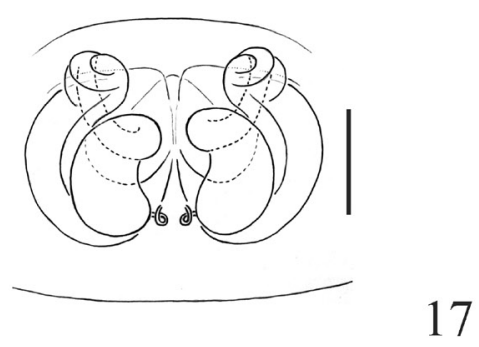

Figs. 15-20. Neopisinus bruneoviridis (Mello-Leitão, 1948). 15, palpo, ventral; epígino: 16, ventral; 17, dorsal. Neopisinus recifensis (Levi, 1964): 18, palpo, ventral; epígino: 19 , ventral; 20, dorsal. Escalas $0,1 \mathrm{~mm}$. 
reconhecidas pelo epígino bem delimitado anteriormente e, internamente, pelos ductos perfazendo duas voltas ao redor das espermatecas (Figs 19, 20).

Nota. A associação de machos e fêmeas foi realizada com base na coloração do abdômen; ambos os sexos foram colecionados juntos em três localidades. O epígino da maioria das fêmeas examinadas está coberto por secreção difícil de ser removida.

Descrição. Macho descrito por LeVI, 1964:12, fig. 8.

Fêmea (IBSP 73328, Murici). Carapaça amareloescura, laterais com pigmento cinza, exceto em larga faixa mediana; área cefálica bem delimitada e região torácica elevada com profunda depressão medianolongitudinal. Quelíceras, clípeo e esterno acinzentados. Pernas amarelas, cinza na porção distal dos fêmures, tíbias e metatarsos. Abdômen oval, sem tubérculos, dorso muito manchado com faixas transversais pretas e, entre elas, e em cada lado, pares de manchas brancas. Ventre marrom-acinzentado.

Olhos subiguais em tamanho; OMA afastados entre si por cerca de três quartos do seu diâmetro e muito próximos aos OLA. Olhos médios posteriores distantes um do outro e dos OLP por cerca do raio dos OMA. Altura do clípeo aproximadamente dois diâmetros dos OMA.

Medidas. Comprimento total 4,50. Carapaça, comprimento 1,50, largura 1,30. Abdômen, comprimento 3,25 , maior largura, 2,50. Pernas, fórmula 1423. Comprimento perna I: fêmur 2,55; patela+tíbia 2,80; metatarso 2,85 ; tarso 0,95 . II: 1,$60 ; 1,65 ; 1,45 ; 0,70$. III: 1,$10 ; 1,15 ; 1,05 ; 0,60$. IV: 2,$50 ; 2,50 ; 2,65 ; 0,95$. Comprimento total: 9,$15 ; 5,40 ; 3,90 ; 8,60$.

Variação. Comprimento total 4,25-5,00. Comprimento da carapaça das fêmeas $(\mathrm{n}=10)$ 1,48-1,60. Fêmur I: 2,3-2,95. No dorso do abdômen de uma fêmea predominaram retículos brancos.

Distribuição. Nordeste do Brasil (Pernambuco, Paraíba, Alagoas e Bahia).

Material adicional examinado. BRASIL, Paraíba: Areia (Reserva da Mata do Pau Ferro), 2 ô, o, 23-29.IX.1999, A. D. Brescovit et al. col. (IBSP 50537, 50544, 50489) e 2 ๙ิ (MCN 43467, 43468); Alagoas: Murici (Estação Ecológica de Murici), ô, 4 ค , 1322.IX.2003, Equipe Biota col. (IBSP 73328, 85753-85755) e $\widehat{\jmath}, 4$ ㅇ (MCN 43464-43466); Bahia: Una (Reserva Biológica de Una), 2 ふै, ㅇ, 13.IV.1998, A. D. Brescovit et al. col. (IBSP 18206, 18337, 18373).

Agradecimentos. Aos curadores das coleções examinadas pelo empréstimo de material. Aos consultores pelas sugestões ao texto. Este trabalho é parte do Programa BIOTA/FAPESP - Programa virtual de Biodiversidade (www.biotasp.org.br). À FAPESP pela bolsa de PósDoutorado (processo 2011/02036-7) concedida a Everton N. L. Rodrigues.

\section{REFERÊNCIAS BIBLIOGRÁFICAS}

Agnarsson, I. 2004. Morphological phylogeny of cobweb spiders and their relatives (Araneae, Araneoidea, Theridiidae). Zoological Journal of the Linnean Society 141(4):447-626.

Agnarsson, I.; Coddington, J. A. \& Knoflach, B. 2007. Morphology and evolution of cobweb spider male genitalia (Araneae, Theridiidae). The Journal of Arachnology 35:334-395.

Arnedo, M. A; Coddington, J.; Agnarsson, I. \& Gillespie, R. G. 2004. From a comb to a tree: phylogenetic relationships of the combfooted spiders (Araneae, Theridiidae) inferred from nuclear and mitochondrial genes. Molecular Phylogenetics and Evolution 31(1):225-245.

Bonaldo, A. B.; Marques, M. A. L.; Pinto-da-Rocha, R. \& Gardner, T. 2007. Species richness and community structure of arboreal spider assemblages in fragments of three vegetational types at Banhado Grande wet plain, Gravataí River, Rio Grande do Sul, Brazil. Iheringia, Série Zoologia 97(2):143-151.

Brignoli, P. M. 1983. A catalogue of the Araneae described between 1940 and 1981. Manchester, Manchester University. 755p.

Bryant, E. B. 1940. Cuban Spiders in the Museum Comparative Zoology. Bulletin of the Museum of Comparative Zoology 86:247-254

Buckup, E. H. \& Marques, M. A. L. 1992. Aranhas Theridiidae da Ilha de Maracá, Roraima, Brasil. III. Gêneros Chrysso e Episinus. Iheringia, Série Zoologia (72):121-125.

Cambridge, F. O. P.-. 1902. Arachnida-Araneida and Opiliones. In: Biologia Centrali-Americana, Zoology. London. v.2, p.313-424.

CAmbridge, O. P.-. 1893. Arachnida - Araneida. In: Biologia CentraliAmericana, Zoology. London. v. 1, p.105-120.

. 1894. Arachnida - Araneida. In: Biologia Centrali-Americana, Zoology. London. v. 1, p.121-144.

1896. Arachnida - Araneida. In: Biologia Centrali-Americana, Zoology. London v.1, p.161-224.

Keyserling, E. 1884. Die Spinnen Amerikas. Theridiidae. Nürnberg, Bauer \& Raspe. v. 2, part 1, 222p.

KNoflach, B. 1993. Das Männchen von Episinus theridioides Simon (Arachnida:Araneae, Theridiidae). Mitteilungen der Schweizerischen Entomologischen Gesellschaft (66):359366.

Knoflach, B. \& Thaler, K. 2000. Notes on Mediterranean Theridiidae (Araneae) - I. Memorie della Società Entomologica Italiana 78(2):411-442.

Levi, H. W. 1955. The spider genera Episinus and Spintharus from North America, Central America and West Indies (Araneae: Theridiidae). Journal of the New York Entomological Society 62:65-90.

1964. American spiders of the genus Episinus (Araneae: Theridiidae). Bulletin of the Museum of Comparative Zoology 131(1): $1-25$

1967a. The theridiid spider fauna of Chile. Bulletin of the Museum of Comparative Zoology 136(1):1-20.

1967b. Habitat observations, records, and new South American Theridiid spiders (Araneae, Theridiidae). Bulletin of the Museum of Comparative Zoology 136(2):21-37.

Mello-Leitão, C. F. DE. 1948. Contribuição ao conhecimento da fauna araneológica das Guianas. Anais da Academia Brasileira de Ciências 20(2):151-196.

Platnick, N. I. 2011. The world spider catalog, version 12.0. American Museum of Natural History. Disponível em: $<\mathrm{http} / /$ research.amnh.org/iz/spiders/catalog>. Acesso em: 15.08.2011.

RicetTi, J. \& Bonaldo, A. B. 2008. Diversidade e estimativas de riqueza de aranhas em quatro fitofisionomias na Serra do Cachimbo, Pará, Brasil. Iheringia, Série Zoologia 98(1):88-99.

Roewer, C. F. 1942. Katalog der Araneae von 1758 bis 1940. Bremen, Natura. v. 1, 1040p.

Simon, E. 1894. Histoire Naturelle des Araignées. Paris. v.1, p.488592.

Wunderlich, J. 1986. Spinnenfauna Gestern und Heute; Fossile Spinnen in Bernstein und ihre heute lebenden Verwandten. Wiesbaden, Bauer Verlag bei Quelle \& Meyer. 283p. 